\title{
A prática do empreendedorismo na Gestão de Design: caso prêmio Ratel
}

\author{
The Practice of Entrepreneurship in Design Management: Prize Ratel Case
}

MUNIZ, Marco Ogê; Mestre; Universidade Federal de Santa Catarina (UFSC)

marcooge@gmail.com

\section{Resumo}

O artigo relata a experiência de aplicação do Prêmio Ratel de empreendedorismo na Gestão de Design, um desafio lançado na disciplina Gestão de Design, do sexto período do curso de Design Gráfico da Universidade do Vale do Itajaí (Univali) - Campus Balneário Camboriú. A proposta do desafio foi inserir os acadêmicos na prática do empreendedorismo utilizando estratégias de Gestão de Design e Inovação. O prêmio foi inspirado em um exercício desenvolvido por Tina Seeling, professora de criatividade e inovação da Universidade de Stanford. Os resultados demonstram que a capacidade empreendedora pode ser estimulada na prática.

Palavras Chave: Inovação, Gestão de Design, Empreendedorismo e Gestão.

\begin{abstract}
The paper reports the experience of applying the Ratel award of Entrepreneurship in Design Management, a challenge launched in the discipline Design Management, of the sixth period of the Graphic Design course at the University of the Itajaí Valley (Univali) - Balneário Camboriú Campus. The proposal of the challenge was to insert the academics in the practice of entrepreneurship using strategies of Design Management and Innovation. The award was inspired by an exercise developed by Tina Seeling, Professor of creativity and innovation at Stanford University. The results show that entrepreneurship can be stimulated in practice.
\end{abstract}

Keywords: Innovation, Design Management, Entrepreneurship and Management. 


\section{Introdução}

Apesar de diversos cursos de graduação em Design no Brasil, nas mais variadas especificidades (Design de Produto, Design Gráfico, Design de Moda, Design de Interiores, Design de Jogos, Design de animação, etc.), inserirem no perfil do egresso competências ligadas a capacidade empreendedora, o empreendedorismo ainda é pouco explorado no nível superior em Design. Na resolução no 5, de 8 de março de 2004, do Conselho Nacional de Educação / Câmara de Educação Superior do Ministério da Educação (MEC), que estabelece as diretrizes curriculares dos cursos superiores de Design no País, a lista de habilidades e competências não faz menção ao empreendedorismo.

Seguindo a resolução citada acima, os projetos pedagógicos, em sua organização curricular, apresentam conteúdos e atividades interligados aos seguintes eixos de formação:

I - conteúdos básicos: estudo da história e das teorias do Design em seus contextos sociológicos, antropológicos, psicológicos e artísticos, abrangendo métodos e técnicas de projetos, meios de representação, comunicação e informação, estudos das relações usuário/objeto/meio ambiente, estudo de materiais, processos, gestão e outras relações com a produção e o mercado;

II - conteúdos específicos: estudos que envolvam produções artísticas, produção industrial, comunicação visual, interface, modas, vestuários, interiores, paisagismos, design e outras produções artísticas que revelem adequada utilização de espaços e correspondam a níveis de satisfação pessoal;

III - conteúdos teórico-práticos: domínios que integram a abordagem teórica e a prática profissional, além de peculiares desempenhos no estágio curricular supervisionado, inclusive com a execução de atividades complementares específicas, compatíveis com o perfil desejado do formando.

Desse modo, os cursos superiores de Design brasileiros têm formado profissionais com alta capacidade técnica e com baixa capacidade empreendedora. Por outro lado, há diversos exemplos de egressos que se ariscam a montar seus próprios negócios (escritórios e agências de design), mesmo sem terem aprendido isso em seus cursos de formação. Há necessidade, portanto, de inserção do empreendedorismo na graduação em design, para que o profissional formado possa empreender tanto seus negócios quanto sua carreira.

Para suprir essa lacuna e desenvolver nos acadêmicos da disciplina Gestão de Design, do curso de Design Gráfico da Universidade do Vale do Itajaí (Univali) - Campus Balneário Camboriú, foi lançado um desafio: o Prêmio Ratel de empreendedorismo na Gestão de Design. O desafio foi inspirado em um exercício desenvolvido por Tina Seeling ${ }^{1}$, professora de criatividade e inovação da Universidade de Stanford. O presente artigo relata a experiência de aplicação do desafio, apresentando a descrição das etapas, as atividades desenvolvidas e os resultados alcançados.

\footnotetext{
${ }^{1}$ A Dra. Tina Seelig é professora da Prática no Departamento de Ciência e Engenharia de Gestão (MS\&E) da Universidade de Stanford. Ela também é diretora do Stanford Technology Ventures Program (STVP), o centro de empreendedorismo da Escola de Engenharia da Universidade de Stanford. Ela leciona cursos sobre criatividade, inovação e empreendedorismo na MS\&E e no Hasso Plattner Institute of Design (d.school) em Stanford.
} 


\section{O Empreendedorismo no Curso de Design Gráfico da Univali}

O Bacharelado em Design Gráfico da Univali - Campus BC, possui três anos e meio de duração, divididos em sete períodos, com disciplinas ofertadas semestralmente. O objetivo geral do curso é:

Formar profissionais de design críticos, éticos e socialmente responsáveis, por meio de um ensino de vanguarda, utilizando-se da pesquisa, do ensino e da extensão como forma de gerar soluções inovadoras em Design Gráfico e que contribuam para o desenvolvimento da sociedade e suas instituições, valorizando a criatividade e a cultura como elementos essenciais para esse processo (PPC, 2017).

Já o perfil do egresso é:

Profissional criativo que elabore projetos gráficos articulando estética, simbologia, sustentabilidade e funcionalidade, planeje e execute a programação visual de diversas mídias, produza, crie e edite infográficos, páginas e portais da Internet e animações em meio digital, podendo atuar em escritórios de design, agências de comunicação, empresas jornalísticas e produtoras cinematográficas, sensível às necessidades psicossociais e ambientais, interpretando fenômenos mercadológicos e culturais, veiculando tecnologias e interagindo com outras áreas de conhecimento, pensando em um âmbito global e agindo localmente (PPC, 2017).

Percebe-se, portanto, que tanto o objetivo geral do curso quanto o perfil do egresso foram desenhados para formar designers que atendam a uma demanda das empresas, escritórios e agências de design. O foco está em desenvolver habilidades e competências técnicas. As características voltadas à gestão e ao empreendedorismo ainda são aspectos secundários.

A disciplina Gestão de Design faz parte do sexto período. Trata-se de uma disciplina de quatro créditos (60 horas). A ementa é a seguinte: "Gestão do processo de design. Relação entre Design e Qualidade. Ferramentas gerenciais. Estratégias de Design". Já o objetivo geral da disciplina é:

Compreender a Gestão do processo de Design como elemento estratégico nas ações de planejamento, qualidade, eficácia aplicadas no mercado de consumo e produção. Interpretar as estratégias de ações envolvidas na gestão do design e suas ferramentas gerencias e aplicá-las em projeto (PEA, 2017).

Uma das competências a serem desenvolvidas nos acadêmicos durante a disciplina foi a capacidade empreendedora. Para tanto, foi lançada um desafio chamado Prêmio Ratel de empreendedorismo na Gestão de Design. Inspirado em uma atividade desenvolvida por Tina Seelig, professora de criatividade e inovação da Universidade de Stanford, o desafio consiste em os acadêmicos venderem, durante duas semanas, qualquer coisa com um investimento de 10 reais.

O objetivo foi obter a maior lucratividade possível utilizando apenas investimentos oriundos dos lucros do investimento inicial. No exercício original de Seelig os acadêmicos tinham duas horas para entregar os resultados. Na atividade descrita no artigo, foi dado um prazo de duas semanas já que um dos requisitos da atividade era a aplicação de estratégias de Gestão de Design, apresentadas na disciplina, de modo a maximizar o processo.

Os quatro pilares da educação, apresentados no relatório da UNESCO sobre a educação para o século XXI, são: o saber, ligado aos aprendizados teóricos; o fazer, ligado aos aprendizados práticos; o ser, ligado aos aprendizados individuais para seu desenvolvimento integral; e o conviver, ligado ao compartilhamento de aprendizados coletivamente (DELORS, 2012). Existe ainda um quinto pilar, proposto por Leal (2009), o empreender, o qual refere-se tanto à capacidade de empreender os outros quatro pilares quanto à capacidade empreendedora voltada à negócios.

Estratégias de marketing combinadas às estratégias de design formam um importante papel 
para a elevação da competitividade das organizações e crescimento de mercado (KOTLER e RATH, 2011). Assim como "a estratégia designer-empreendedor é 'inata' à ideia do fundador e próxima da estratégia empresarial" (MOZOTA, 2011, p. 294) e a relevância do design no contexto econômico está relacionada à contribuição da atividade na competitividade, inovação, diferenciação, qualidade e satisfação dos usuários (MARTINS e MERINO, 2008). Nesse contexto surge o designer estrategista, profissional que promove serviços de inovação estratégica e mudança nos negócios (COOPER, EVANS e WILLIAMS, 2011).

Então, uma das propostas do desafio Ratel foi inserir o acadêmico em campo para que ele pudesse aprimorar a capacidade empreendedora na prática. Previamente os alunos aprenderam estratégias de gestão, as quais poderiam ser utilizadas como ferramentas de auxílio no processo.

\section{O método de aplicação do Prêmio Ratel}

O desafio Ratel foi aplicado no mês de maio de 2017, durante o primeiro semestre, na disciplina Gestão de Design, em período noturno, do sexto período do Curso de Design Gráfico da Univali - Campus BC. A turma contava com 14 acadêmicos, que foram divididos em três equipes. A atividade foi desenvolvida no segundo módulo da disciplina "Relação entre Design e Qualidade", para cumprir o subtópico "Design e Inovação".

A primeira etapa do processo consistiu na apresentação do prêmio. Uma aula foi destinada à explicação da proposta do desafio, com o delineamento dos objetivos, dos requisitos e das restrições da atividade. Após a explanação, os acadêmicos definiram as equipes com seus respectivos integrantes e o artefato que seria comercializado em campo. Foram formadas três equipes, cujas temáticas e integrantes seguem listados na tabela a seguir.

Tabela 1: temáticas e integrantes das equipes de projeto.

\begin{tabular}{l|l|l|}
\multicolumn{1}{|c|}{ Temática } & \multicolumn{1}{c|}{ Integrantes } \\
\hline Venda de brigadeiro & $\begin{array}{l}\text { Ariana Regina Ferreira, Diana Gustamann Mascarello, Eliza Viana De } \\
\text { Melo, Mabel De Miranda Pogere e Mariana Goncalves Avila. }\end{array}$ \\
\hline Venda & de & $\begin{array}{l}\text { Ana Luisa Pulcinelli, Anielli Martiniano Lemos, Danrley Garcia Siqueira, } \\
\text { sketchcards }\end{array}$ \\
\hline Venda de suco & $\begin{array}{l}\text { Barbara Kanigoski Deparis, Belkis Stertz Soares, Leandro Paula Ribeiro } \\
\text { detox }\end{array}$
\end{tabular}

Fonte: acervo do autor.

O professor da disciplina forneceu $\mathrm{R} \$ 10,00$ (dez reais) para os acadêmicos iniciarem as atividades, com a prerrogativa de que no prazo de duas semanas, dia da apresentação dos resultados, os alunos devolvessem o valor investido. Também foi fornecida uma declaração assinada pelo professor para permitir a venda dos artefatos. A equipe vencedora era a que obtivesse maior lucratividade. Foi utilizado o loop do hábito, princípio da motivação > rotina > recompensa, 
para estimular a disputa. Um estímulo pode servir de motivação necessária para a adoção de um comportamento que conduz a uma recompensa (Duhigg, 2012).

Figura 1: troféu, medalha e certificado do Prêmio Ratel.

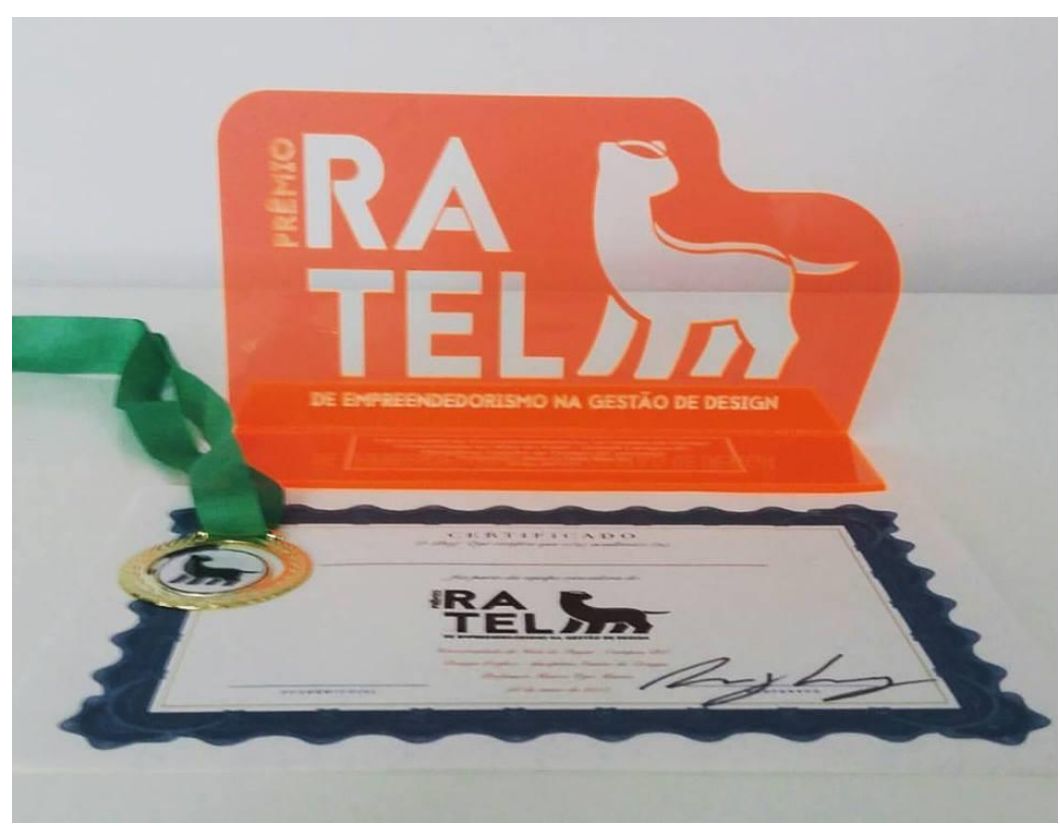

Fonte: acervo do autor.

Dessa forma, os acadêmicos foram motivados a dedicar-se a atividade, pois a equipe vencedora receberia uma premiação composta por troféu, medalhas e certificados de primeiro colocado. Já a equipe que ficasse em segundo lugar receberia certificados de segundo colocado. A equipe terceira colocada ficaria sem premiação. Todos os acadêmicos receberam notas pelo trabalho desenvolvido.

O acadêmico Danrley Garcia Siqueira voluntariou-se a desenvolver a identidade visual do desafio. Para a escolha do mascote da premiação foi respondido um quiz cuja resultado apresentou o animal que melhor representa o espírito empreendedor da turma: o animal Ratel.

Figura 2: logotipo do Prêmio Ratel.

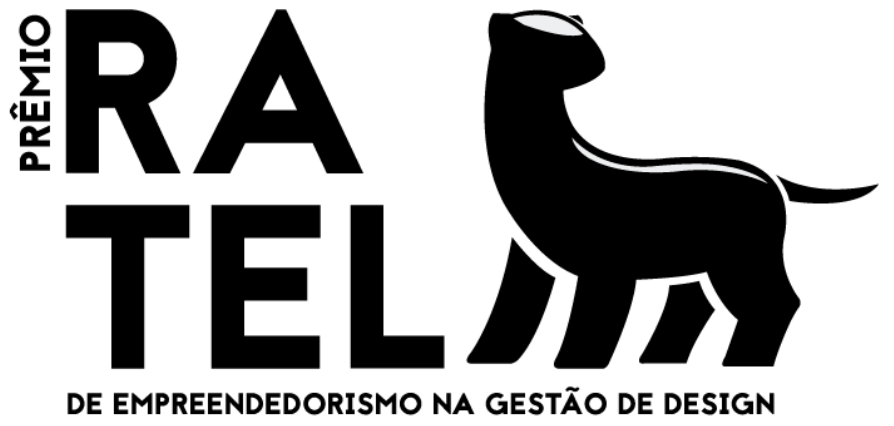

Fonte: acervo do autor. 
A partir das orientações iniciais os acadêmicos foram a campo para realizarem a atividade. Estipulou-se que, no prazo de duas semanas, os alunos fariam a exposição dos resultados para a turma por meio de apresentação de seminários. Na data das apresentações foram entregues as premiações aos vencedores. Além disso, foram encomendadas pizzas salgadas e doces para estimular a confraternização.

\section{Os resultados do Prêmio Ratel}

A equipe terceira colocada do desfio foi a responsável pela venda de sucos Detox. Os acadêmicos relataram que tiveram alguns problemas porque os integrantes se separaram para vender em diferentes locais. Além disso, os alunos foram impedidos de vender no seu ponto de venda principal, uma academia de ginástica, por questões legais. Abaixo segue a tabela que resume os resultados da equipe.

Tabela 2: números da equipe responsável pela venda de suco Detox.

\begin{tabular}{|l|l|} 
& Em reais (R\$) \\
\hline Receita & 147,00 \\
\hline Despesas & 57,00 \\
\hline Lucro & 90,00
\end{tabular}

Fonte: acervo do autor.

Além do investimento inicial no valor de $\mathrm{R} \$ 10,00$ (dez reais), os integrantes da equipe Detox também injetaram recursos próprios na tentativa de aumentar a receita. Contudo, os problemas enfrentados pela equipe proporcionaram um lucro abaixo das demais equipes.

A equipe segunda colocada foi responsável pela venda de brigadeiros. Ao contrário da equipe terceira colocada, produziram os primeiros brigadeiros utilizando apenas o investimento inicial no valor de $\mathrm{R} \$ 10,00$ (dez reais). Os brigadeiros foram vendidos no próprio Campus da Univali e foram produzidos pelos próprios acadêmicos. Abaixo segue a tabela que resume os resultados da equipe.

Tabela 3: números da equipe responsável pela venda de brigadeiros.

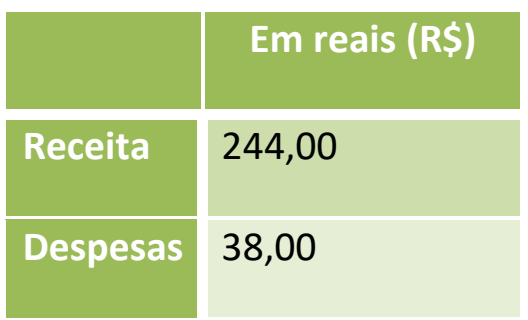


Fonte: acervo do autor.

A equipe segunda colocada também desenvolveu um material de divulgação, que foi veiculado nas mídias sociais (Instagram, Facebook, WhatsApp, etc.). Os brigadeiros foram vendidos pelo valor de $\mathrm{R} \$ 1,00$ (um real) durante o horário de intervalo das aulas, conforme mostra a figura abaixo.

Figura 3: material de divulgação da equipe responsável pela venda de brigadeiros.

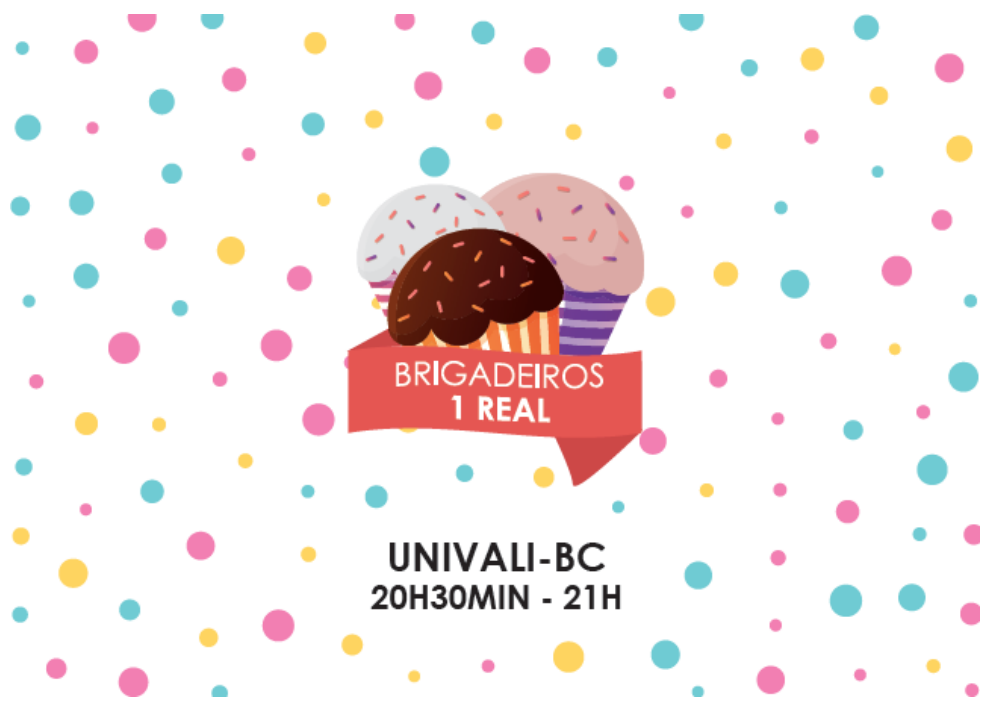

Fonte: acervo do autor.

Já a equipe primeira colocada foi responsável pela venda de sketchcards. Além dos sketchcards também eram vendidos pôsteres e adesivos, todos desenvolvidos e assinados por Dan Siqueira (o acadêmico Danrley Garcia Siqueira). Os artefatos foram vendidos no Campus da Univali de diferentes maneiras. 
Figura 4: histórias do Instagram da equipe responsável pela venda de sketchcards.

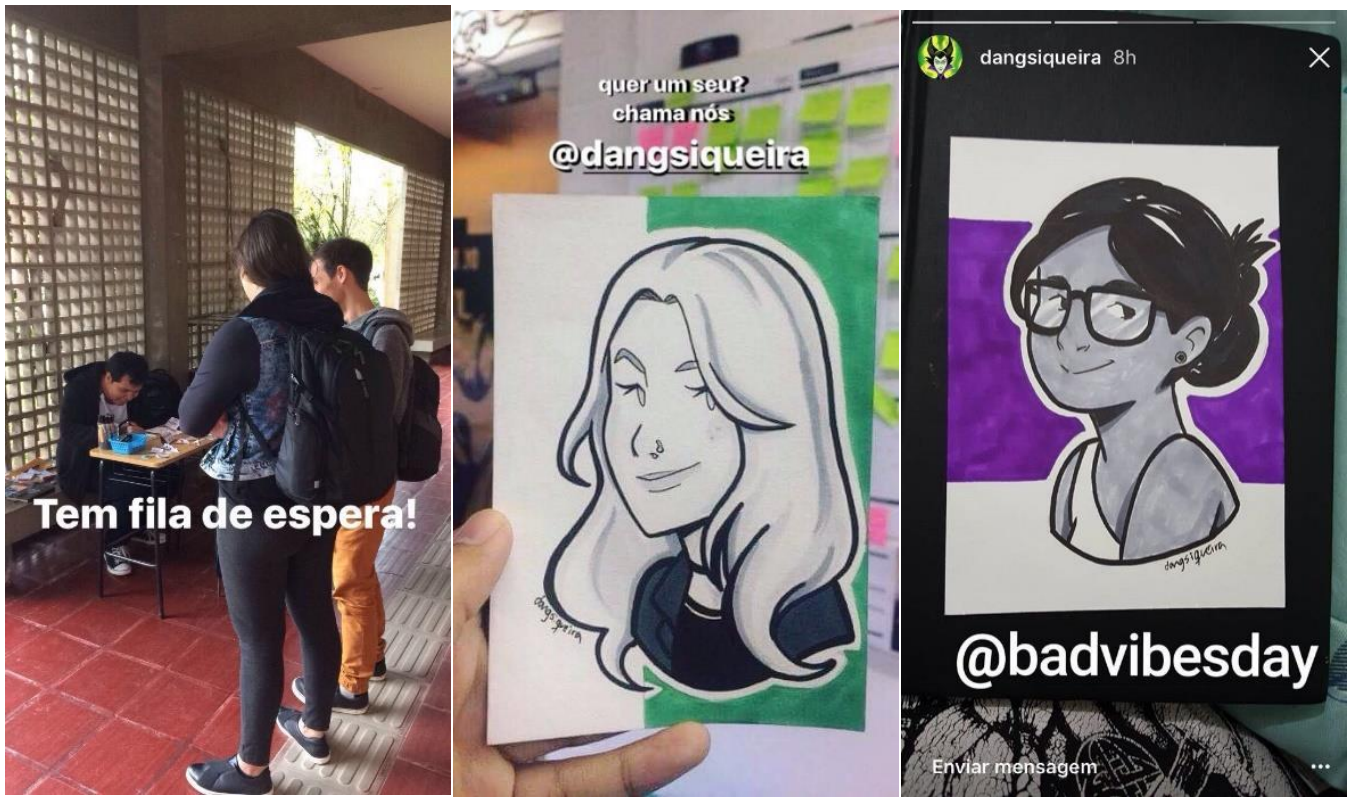

Fonte: acervo do autor.

A primeira estratégia de vendas da equipe vencedora foi montar um stand no corredor principal do Campus com os produtos e o desenho instantâneo de sketchcards. No sentido de elevar as vendas, foram utilizadas mais duas estratégias: a propaganda boca a boca, por meio da qual os integrantes da equipe ofereciam seus produtos aos colegas; e o compartilhamento nas redes sociais, por meio do qual foram escolhidos amigos influentes e com bastante seguidores para divulgar o trabalho para seus conhecidos.

Figura 5: compartilhamento da venda de sketchcards.
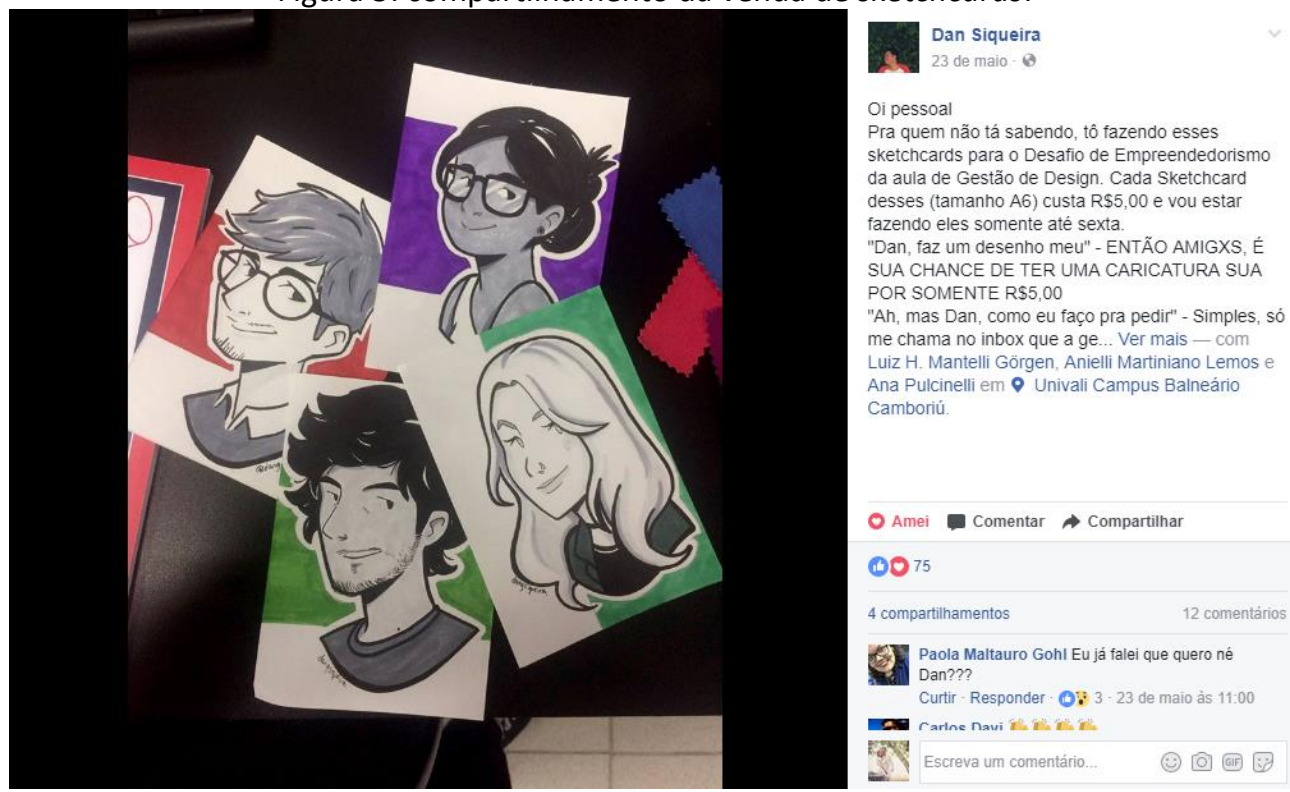

Fonte: acervo do autor. 
Essas duas últimas estratégias elevaram significativamente as encomendas, ao ponto de a equipe concentrar-se, quase integralmente, ao desenvolvimento e a venda dos sketchcards.

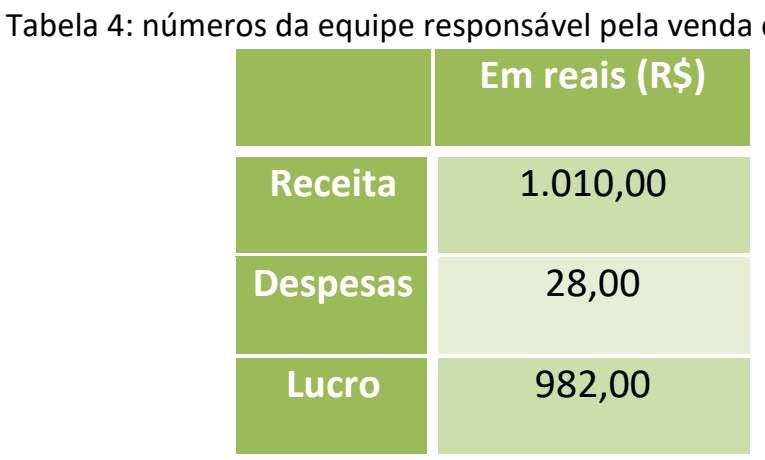

Fonte: acervo do autor.

Um dos fatores que determinaram o sucesso dos sketchcards foi o seu estilo, assinado por Dan Siqueira. A condicionante do estilo seguiu um dos conteúdos discutidos em aula, estabelecido por Baxter (2008), a partir do qual o produto deve chamar a atenção por ser visualmente agradável, deve ser desejável e atrativo.

\section{O princípio da motivação e recompensa}

No dia da premiação os acadêmicos compartilharam seus resultados, suas estratégias, suas dificuldades e suas sugestões de melhoria com relação ao desafio. A turma foi recebida com pizzas salgadas e doces, refrigerantes e sucos, para estimular a confraternização.

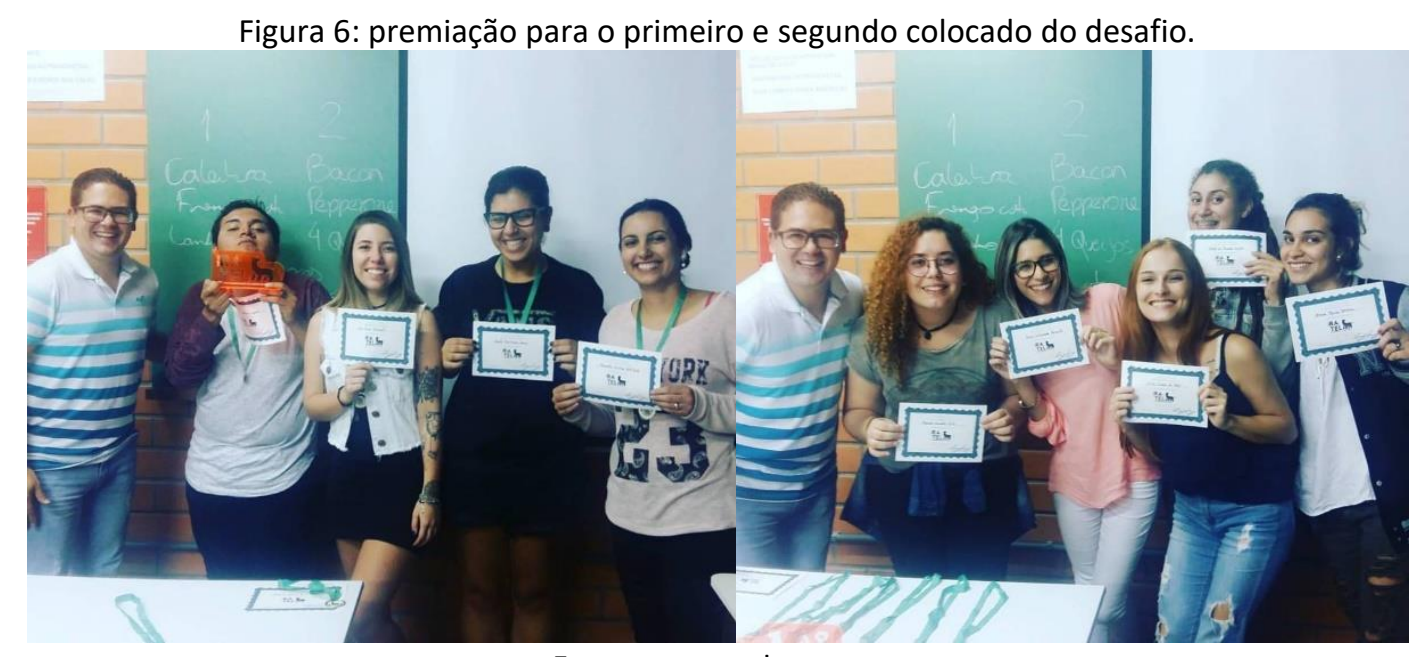

Fonte: acervo do autor.

Contatou-se que as equipes que utilizaram estratégias de gestão para gestionar o processo foram as que obtiveram os melhores resultados. A equipe que mais variou as estratégias de venda foi a equipe vencedora. Do mesmo modo, a equipe que dependeu de um único ponto de venda foi a que obteve o pior resultado. 
Com relação às sugestões de melhoria, os acadêmicos relataram que nos próximos desafios seria interessante limitar os artefatos de venda a produtos que possuem ligação com o design. Também sugeriram que o número de integrantes das equipes fosse reduzido a trios, para que houvesse uma maior variedade de grupos. Por fim, lamentaram que o curso não possui mais disciplinas e atividades voltadas à pratica do empreendedorismo.

\section{Aplicações em 2017-2}

Em 2017-2, foram acatadas as sugestões de melhoria propostas pelos acadêmicos da turma anterior: limitar os artefatos de venda a produtos que possuem ligação com o design, redução do número de integrantes das equipes para trios para aumentar a variedade de grupos e estimular mais a prática do empreendedorismo na disciplina e no curso de Design.

Além disso, na disciplina foram disponibilizados momentos de aula para a definição de metas de negócio, para a elaboração de estratégias de gestão e para e a exploração do processo criativo na geração de ideias inovadoras de soluções.

Desta vez, as soluções foram mais criativas e se concentraram na exploração de habilidades e competências ligadas ao design. Os artefatos vendidos foram: cartões com mensagens aleatórias, carteiras de papel personalizado, cases para celular customizados, chaveiro em formato de kirigami, sketchcards digitais e caixa de fósforo com artes gráficas.

Figura 7: Artefatos da turma 2017-2.

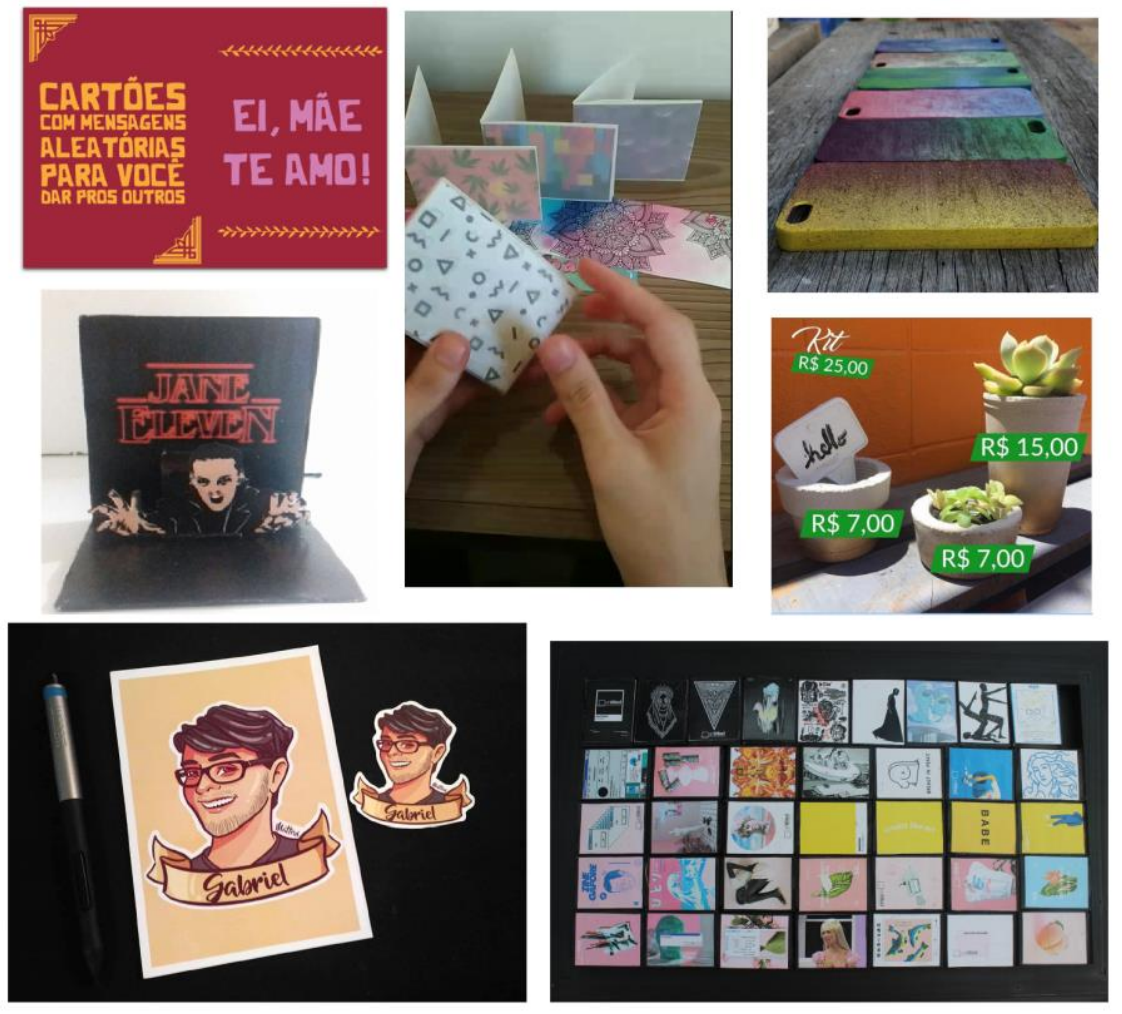

Fonte: acervo do autor. 
Os vencedores do Prêmio Ratel 2017/2 foram os segintes: primeiro Mariana Mattevi com a venda de sketchcards digitais (lucro de 2100 reais); segundo lugar Gustavo, Jaicieli e Bruna com a venda de carteiras de papel (lucro de 347 reais) e terceiro lugar Gionava, Isabella e Desiree com a venda de vasos de cimento (lucro de 120 reais).

\section{Considerações finais}

O objetivo do presente artigo foi relatar a experiência de aplicação do Prêmio Ratel de empreendedorismo na Gestão de Design, um desafio lançado na disciplina Gestão de Design, do sexto período do curso de Design Gráfico da Universidade do Vale do Itajaí (Univali) - Campus Balneário Camboriú. A proposta do desafio foi inserir os acadêmicos na prática do empreendedorismo utilizando estratégias de Gestão de Design e Inovação. O prêmio foi inspirado em um exercício desenvolvido por Tina Seeling, professora de criatividade e inovação, da Universidade de Stanford.

Os resultados demonstraram que os acadêmicos da disciplina Gestão de Design podem desenvolver habilidades e competências empreendedoras na prática, aplicando aprendizados teóricos desenvolvidos em salada de aula. As equipes que utilizaram estratégias de gestão para gestionar o processo foram as que obtiveram os melhores resultados. A equipe que mais variou as estratégias de venda foi a equipe vencedora. Do mesmo modo, a equipe que dependeu de um único ponto de venda foi a que obteve o pior resultado.

A equipe vencedora desenvolveu uma solução que combina os conteúdos de gestão de design apresentados em aula: artefato que chama a atenção por ser visualmente agradável, desejável e atrativo (Baxter, 2008); e a abordagem do designer estrategista, profissional que promove serviços de inovação estratégica e mudança nos negócios (COOPER, EVANS e WILLIAMS, 2011).

O desafio, além de estimular por meio de um exercício prático o desenvolvimento dos quatro pilares da educação - o saber, o fazer, o ser e o conviver (DELORS, 2012); também estimulou o desenvolvimento do quinto pilar, o empreender, tanto pela promoção da capacidade de empreender os outros quatro pilares quanto pela promoção da capacidade empreendedora voltada à negócios (Leal, 2009) nos acadêmicos.

As sugestões de melhoria propostas pelos acadêmicos da turma, limitar os artefatos de venda a produtos que possuem ligação com o design, redução do número de integrantes das equipes para trios para aumentar a variedade de grupos e estimular mais a prática do empreendedorismo na disciplina e no curso de Design; foram fundamentais para o aperfeiçoamento da atividade.

\section{Referências}

BAXTER, Mike. Projeto de produto: guia prático para o design de novos produtos. 2. ed. rev. São Paulo: Edgard Blücher, 2008.

COOPER, Rachel; EVANS, Martyn e WILLIAMS, Alex. New Design Business Models: implications for the future of Design Management. In: The handbook of Design Management. Edited by Rachel 
Cooper, Sabine Junginger and Thomas Lockwood. Bergpublishers: Oxford, 2011.

DELORS, Jaques. Educação: um tesouro a descobrir; relatório para a UNESCO da Comissão Internacional sobre Educação para o século XXI. São Paulo: Cortez Editora, 2012.

DUHIGG, Charles. O poder do hábito: por que fazemos o que fazemos na vida e nos negócios. Tradução: Rafael Mantovani. Rio de Janeiro: Objetiva, 2012.

KOTLER, Philip e RATH, G. Alexander. Design: a powerful but neglected strategic tool. In: The handbook of Design Management. Edited by Rachel Cooper, Sabine Junginger and Thomas Lockwood. Bergpublishers: Oxford, 2011.

LEAL, Antonio Fernando. Aprender a empreender: um pilar na educação de jovens e adultos. 2009. 145 f. Dissertação (Mestrado em Educação) - Universidade Federal da Paraí-ba, João Pessoa, 2009.

MARTINS, Rosane Fonseca de Freitas; MERINO, Eugenio Andréz Díaz. A Gestão de design como estratégia organizacional. Londrina, PR: Eduel, 2008.

MOZOTA, Brigitte Borja de; KLÖPSCH, Cássia; COSTA, Filipe Campelo Xavier da. Gestão do design: usando o design para construir valor de marca e inovação corporativa. Porto Alegre: Bookman, 2011.

PEA. Plano de Ensino e Aprendizagem. Bacharelado em Design Gráfico, Universidade do Vale do Itajaí - Campus Balneário Camboriú. 2017.

PPC. Projeto Pedagógico de Curso. Bacharelado em Design Gráfico, Universidade do Vale do Itajaí Campus Balneário Camboriú. 2017.

RESOLUÇÃO № 5, DE 8 DE MARÇO DE 2004. CONSELHO NACIONAL DE EDUCAÇÃO / CÂMARA DE EDUCAÇÃO SUPERIOR. Acesso em 15/07/2017. Disponível em: http://portal.mec.gov.br/cne/arquivos/pdf/rces05_04.p 